\title{
Mechanistic insight into the interaction between a titanium dioxide photocatalyst and Pd1 cocatalyst for improved photocatalytic performance
}

\author{
Citation for published version (APA): \\ Su, R., Dimitratos, N., Liu, J., Carter, E., Althahban, S., Wang, X., Shen, Y., Wendt, S., Wen, X., \\ Niemantsverdriet, J. W., Iversen, B. B., Kiely, C. J., Hutchings, G. J., \& Besenbacher, F. (2016).' Mechanistic \\ insight into the interaction between a titanium dioxide photocatalyst and $\mathrm{Pd} 1$ cocatalyst for improved \\ photocatalytic performance. ACS Catalysis, 6(7), 4239-4247. https://doi.org/10.1021/acscatal.6b00982
}

DOI:

10.1021/acscatal.6b00982

Document status and date:

Published: 01/07/2016

\section{Document Version:}

Publisher's PDF, also known as Version of Record (includes final page, issue and volume numbers)

\section{Please check the document version of this publication:}

- A submitted manuscript is the version of the article upon submission and before peer-review. There can be important differences between the submitted version and the official published version of record. People interested in the research are advised to contact the author for the final version of the publication, or visit the $\mathrm{DOI}$ to the publisher's website.

- The final author version and the galley proof are versions of the publication after peer review.

- The final published version features the final layout of the paper including the volume, issue and page numbers.

Link to publication

\footnotetext{
General rights

- You may freely distribute the URL identifying the publication in the public portal. follow below link for the End User Agreement:

www.tue.nl/taverne

\section{Take down policy}

If you believe that this document breaches copyright please contact us at:

openaccess@tue.nl

providing details and we will investigate your claim.
}

Copyright and moral rights for the publications made accessible in the public portal are retained by the authors and/or other copyright owners and it is a condition of accessing publications that users recognise and abide by the legal requirements associated with these rights.

- Users may download and print one copy of any publication from the public portal for the purpose of private study or research.

- You may not further distribute the material or use it for any profit-making activity or commercial gain

If the publication is distributed under the terms of Article $25 \mathrm{fa}$ of the Dutch Copyright Act, indicated by the "Taverne" license above, please 


\section{Mechanistic Insight into the Interaction Between a Titanium Dioxide Photocatalyst and Pd Cocatalyst for Improved Photocatalytic Performance}

Ren Su, ${ }^{\dagger, \ddagger}$ Nikolaos Dimitratos, ${ }^{\S, \|}$ Jinjia Liu, ${ }^{\ddagger, \bigcirc}$ Emma Carter, ${ }^{\perp}$ Sultan Althahban, ${ }^{*}$ Xueqin Wang, ${ }^{\dagger}$ Yanbin Shen, ${ }^{\dagger \neq}$ Stefan Wendt, ${ }^{\dagger}$ Xiaodong Wen, ${ }^{\ddagger, O}$ J. W. (Hans) Niemantsverdriet, ${ }^{\ddagger} \rightarrow$ Bo B. Iversen, ${ }^{\dagger, \nabla}$ Christopher J. Kiely, ${ }^{\#}$ Graham J. Hutchings, ${ }^{*},{ }^{\prime} \|$ and Flemming Besenbacher ${ }^{*}{ }^{\dagger}$

${ }^{\dagger}$ Interdisciplinary Nanoscience Centre (iNANO), Aarhus University, DK-8000 Aarhus C, Denmark

${ }^{\ddagger}$ SynCat@Beijing, SynfuelsChina Co. Ltd., Leyuan South Street II, No.1, Yanqi Economic Development Zone C\#, Huairou District, Beijing 101407, China

${ }^{\S}$ Cardiff Catalysis Institute, School of Chemistry, Cardiff University, Cardiff CF10 3AT, United Kingdom

${ }$ The UK Catalysis Hub, Research Complex at Harwell, Rutherford Appleton Laboratory, Oxfordshire, OX11 0FA, United Kingdom

${ }^{\perp}$ School of Chemistry, Cardiff University, Cardiff CF10 3AT, United Kingdom

\#Department of Materials Science and Engineering, Lehigh University, 5 East Packer Avenue, 18015-3195 Bethlehem, Pennsylvania, United States

${ }^{\nabla}$ Department of Chemistry, Aarhus University, Langelandsgade 140, DK-8000 Aarhus C, Denmark

OState Key Laboratory of Coal Conversion, Institute of Coal Chemistry, CAS, Taiyuan, China

SynCat@DIFFER, Syngaschem BV, Eindhoven, The Netherlands

\section{Supporting Information}

ABSTRACT: Understanding the cocatalyst/semiconductor interaction is of key importance for the design and synthesis of next generation photocatalytic materials for efficient hydrogen production and environmental cleanup applications. Here we investigate preformed Pd nanoparticles (NPs) supported on a series of anatase $\mathrm{TiO}_{2}$ having well-controlled but varying degrees of crystallinity and crystallite size, and explore their photocatalytic performance for $\mathrm{H}_{2}$ production and phenol decomposition. While tuning the anatase crystallite size significantly influences the photocatalytic performance, varying the $\mathrm{TiO}_{2}$ crystallinity shows a negligible effect. Interestingly, the optimum quantum efficiency $(\sim 78 \%)$

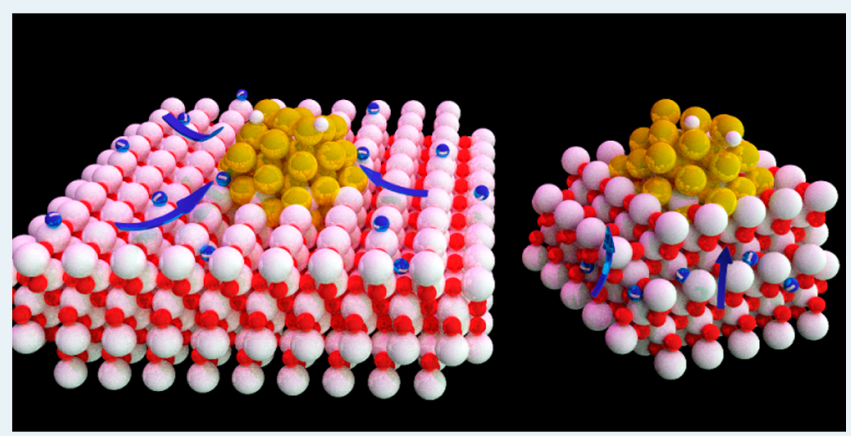
for $\mathrm{H}_{2}$ evolution is achieved with anatase having medium crystallite size $(\sim 16 \mathrm{~nm})$, whereas for phenol decomposition, a promotional effect is only observed for anatase with larger crystallite sizes $(>20 \mathrm{~nm})$. Surface radical species and radical densities study reveal that the photogenerated charge carriers have been trapped at different sites depending on the crystallite size of anatase. While the excited electrons are only trapped in bulk lattice sites in small anatase $(<16 \mathrm{~nm})$, larger anatase particles provide extra surface sites for charge trapping, which benefit charge storage and transportation to Pd surface sites, leading to a more efficient utilization of charge carriers for photocatalysis. Additionally, Pd supported on medium sized anatase $(\sim 16 \mathrm{~nm})$ hinders the formation of $\mathrm{O}_{2}{ }^{\bullet-}$ radicals on $\mathrm{TiO}_{2}$ surfaces, thus preventing unwanted reoxidation of photogenerated $\mathrm{H}_{2}$.

KEYWORDS: photocatalysis, metal-semiconductor interaction, electron spin resonance, hydrogen evolution, phenol decomposition, $\mathrm{TiO}_{2}$ density functional theory

\section{INTRODUCTION}

Investigations of advanced catalytic processes have received significant attention, as the demand for sustainable energy, purified water, and clean air keeps increasing. ${ }^{1-3}$ Photocatalysis employing particulate semiconductor based materials has experienced tremendous research activity due to the potential of using solar energy as the driving force for $\mathrm{H}_{2}$ production, $\mathrm{CO}_{2}$ reduction, and water and air remediation. ${ }^{4-6}$ Numerous photocatalyst materials ranging from simple oxides, ${ }^{7}$ nitrides, ${ }^{8,9}$ or sulfides $^{10,11}$ to complicated mixed phase materials ${ }^{12-14}$ have

Received: April 5, 2016

Revised: $\quad$ May 22, 2016

Published: May 24, 2016 
been developed for various applications; however, their photocatalytic performance still needs to be improved before implementation in industry can be anticipated.

The relatively poor performance of most photocatalyst materials can be directly linked to the kinetics of photoexcited electron-hole $\left(\mathrm{e}^{-}-\mathrm{h}^{+}\right)$pairs within the semiconductor, where most of them recombine rather than being separated and used for redox reactions with the surface adsorbed reactants. ${ }^{15-17}$ Engineering the electronic properties of the photocatalyst by tuning the composition, structure, surface defects (impurities), surface acidity, and polymorph identity may improve the charge transfer dynamics as well as the optical properties of the material to optimize the photocatalytic performance. ${ }^{18-22}$

Decorating the surface of the photocatalyst by metal (i.e., Au, $\mathrm{Pd}, \mathrm{Pt}$ ) nanoparticles (NPs) is considered to be a promising and efficient approach to improve the photocatalytic performance. $^{23,24}$ The presence of metal NPs as a cocatalyst facilitates the spatial separation of the $\mathrm{e}^{-}-\mathrm{h}^{+}$pairs by trapping the excited $\mathrm{e}^{-}$that is transferred from the conduction band (CB) of the semiconductor photocatalysts. ${ }^{25}$ Fundamental investigations of metal-semiconductor systems indicate that the elemental identity, size, and loading of the cocatalyst all influence the kinetics of the charge transfer process therefore affecting the photocatalytic performance. ${ }^{26-29}$

Meanwhile, it has been shown that the nature of the semiconductor support (i.e., polymorph composition, particle size) can also be used to manipulate the electronic properties of the metal NPs and thus lead to tunable photoreactivity and selectivity. ${ }^{30,31}$ While promotional effects have been observed in most cases, ${ }^{31-36}$ inhibition of the catalyst performance has been also noted. ${ }^{37,38}$ This heterogeneity suggests that numerous details of the interplay between semiconductor photocatalyst particles and the cocatalyst NPs are still unclear. It has been wellestablished that well-controlled and deliberately engineered cocatalyst structures can have a significant positive influence the photoreactivity of the system. ${ }^{39,40}$ However, the effect of modifying the semiconductor support to alter the semiconductor/cocatalyst interplay and thus engineering the overall photoreactivity remains largely unknown presumably because of the lack of a well-defined system with tunable physical parameters. Recently, the influence of crystallinity and crystallite size of the pristine anatase $\mathrm{TiO}_{2}$ as the photocatalyst has been investigated, indicating that the reaction pathways of photocatalytic phenol decomposition can be tuned by adjusting the anatasenanocrystallite size. ${ }^{41}$ Since varying the crystallinity and crystallite size can result in changes in the surface properties of anatase, we consider that these parameters may be deliberately controlled to modulate the interaction between metal NPs and semiconductor materials and thus enable fine-tuning of the overall photocatalytic performance of the system.

From the perspective of the reaction mechanism, most photocatalytic processes involve radical species (i.e., $\mathrm{OOH}^{\bullet}$, $\mathrm{OH}^{\bullet}, \mathrm{O}_{2}^{-}$, and $\mathrm{Ti}^{3+}$ ) that are created from the photogenerated $\mathrm{e}^{-}-\mathrm{h}^{+}$pairs. ${ }^{16}$ According to electron spin resonance spectrometry (ESR) analysis, the identity, concentration, and lifetime of radicals are crucial parameters that dictate the photoreactivity and selectivity of the catalyst. ${ }^{30,42,43}$ Surface science studies on model systems have shown that fine-tuning of the cocatalyst/ semiconductor interaction may alter the aforementioned parameters to allow some control over the reaction mechanism. 44,45 Unfortunately, such an investigation is still missing for well-defined systems of real photocatalysts, limiting our understanding of photocatalytic processes and hence the development of high performance photocatalysts.

Here we explore the cocatalyst/semiconductor interaction using preformed Pd NPs supported on well-defined nanoscale anatase $\mathrm{TiO}_{2}$ particles. The Pd NPs prepared by solimmobilization were deposited onto anatase synthesised using a supercritical methodology. ${ }^{46}$ By producing the $\mathrm{TiO}_{2}$ this way we can systematically and independently control the anatase crystallinity $(12 \%-82 \%)$ and mean crystallite size $(6-27 \mathrm{~nm})$. The photocatalytic performance of this matrix of materials was investigated for photocatalytic $\mathrm{H}_{2}$ evolution and phenol decomposition reactions to examine the interaction between the Pd cocatalyst and anatase support particles. In particular, we have probed the interaction mechanisms by following the identity and population density of surface radicals by ESR spectrometry. Additionally, we also employed theoretical calculations to rationalize the origins of the different radical species and to correlate the photocatalytic performance with the electronic properties of the materials.

\section{RESULTS AND DISCUSSION}

Physical Properties of the Photocatalysts. The XRD patterns of samples after immobilization of Pd NPs are shown in Figure 1. Diffraction patterns of $\mathrm{Pd}$ supported anatase
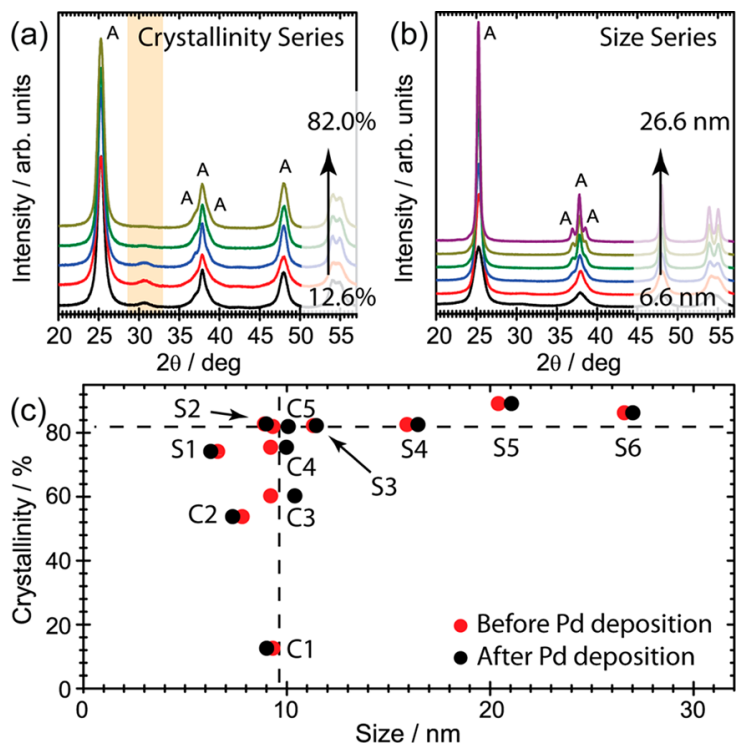

Figure 1. ( $a$ and $b$ ) XRD patterns of as-prepared Pd NPs on anatase $\mathrm{TiO}_{2}$ particles having different crystallinity and mean crystallite size, respectively. "A" indicates the peak positions of anatase. (c) Comparison of the mean crystallite size of anatase before and after Pd immobilization as derived from Scherrer analysis of the XRD patterns. On the basis of comparisons of the XRD patterns, the crystallinity and mean crystallite size of anatase particles were considered to be unchanged after Pd addition. $^{41,48}$

samples with variable crystallinity (Figure 1a) and crystallite size (Figure $1 b$ ) remained almost identical compared to that of their pristine anatase equivalent (Figure S1) ${ }^{41}$ indicating that the solimmobilization process did not significantly alter the structure, mean crystallite size, or crystallinity of the anatase particles (Figure 1c). The diffraction peaks of Pd were not observed in all cases due to its ultrasmall size and low loadings (1 wt \%). However, we do observe a very broad peak located at $\sim 32^{\circ}$ (yellow zone in Figure 1a) within low crystallinity samples (i.e., $12.6 \%-60 \%)$, which can be tentatively assigned to $\mathrm{PdO}(101) .{ }^{47}$ 
Meanwhile, PdO was not observed within the highly crystalline samples (Figure $1 \mathrm{~b}$ ), indicating the $\mathrm{Pd}^{0}$ sol supported on a more disordered $\mathrm{TiO}_{2}$ surface tends to become more oxidized at ambient conditions.

A subset of $\mathrm{Pd} / \mathrm{TiO}_{2}$ catalyst samples was examined in some detail using an aberration corrected STEM. A typical low magnification $\mathrm{HAADF}$ image from the $\mathrm{Pd} / \mathrm{TiO}_{2}$ (sample S6) photocatalyst is shown in Figure 2a. It is clear that the dispersion

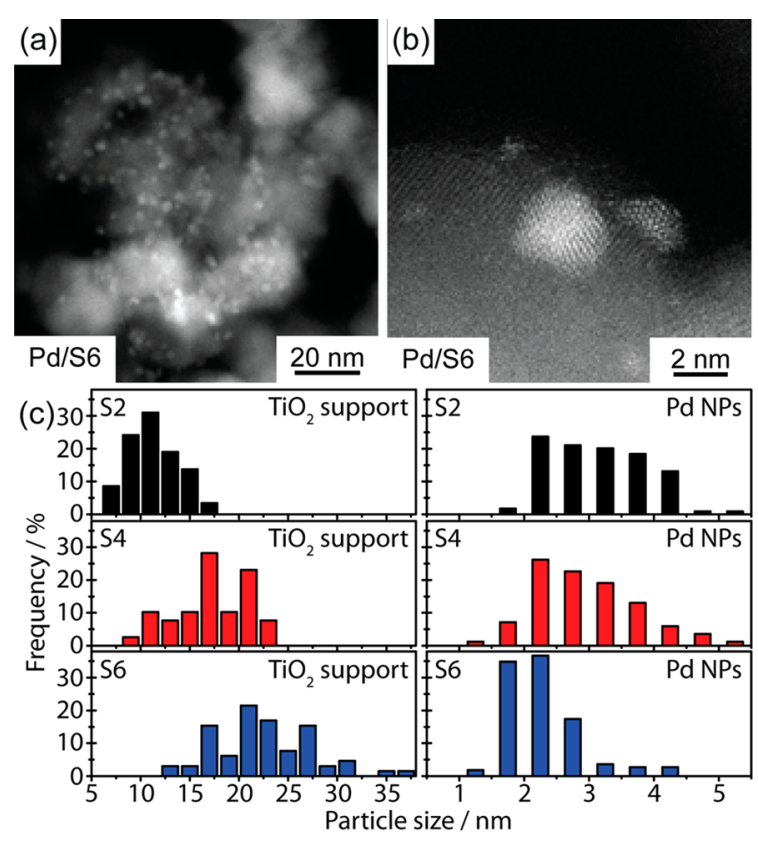

Figure 2. (a, b) Representative BF- and HAADF-STEM images of Pd on $\mathrm{TiO}_{2}$ (sample S6). (c) Particle size distributions of the $\mathrm{TiO}_{2}$ particles and Pd NPs of samples S2, S4, and S6.

of $\mathrm{Pd} \mathrm{NPs}$ on $\mathrm{TiO}_{2}$ resulting from the sol-immobilization process is not particularly homogeneous, where some grains are more highly decorated with Pd cocatalyst NPs than others. Higher magnification HAADF images (Figure $2 b$ ) clearly show that the $\mathrm{Pd}$ NPs have a tendency to "wet" the $\mathrm{TiO}_{2}$, forming an extended flat interface. In addition to the metallic Pd NPs, it was relatively easy to observe sub-nanometer Pd-containing clusters dispersed on anatase that were much smaller than the original colloid size.The formation of flattened interfaces and sub-nanometer clusters suggests that some PVA-ligand disruption and $\mathrm{Pd}$ diffusion has occurred during the drying process $\left(120{ }^{\circ} \mathrm{C}\right.$ for $16 \mathrm{~h})$. Similar Pd cocatalyst morphologies and dispersions were found in other $\mathrm{Pd} / \mathrm{TiO}_{2}$ samples irrespective of the degree of crystallinity or the mean crystallite size of $\mathrm{TiO}_{2}$ support (see Figures S1-S4 of samples C1, S2, S4, and S6 in the Supporting Information). ${ }^{48}$ The particle size distributions of $\mathrm{TiO}_{2}$ in the three $82 \%$ crystallinity samples (S2, S4, and S6) are plotted in Figure 2c and show very good agreement with the mean crystallite size analysis derived from the XRD measurements, indicating that sintering and agglomeration of the $\mathrm{TiO}_{2}$ particles during $\mathrm{Pd}$ immobilization is negligible. Although there is some degree of overlap between samples S2, S4, and S6, it is fair to say that samples S2, S4, and S6 are mainly composed of small to medium $(5-15 \mathrm{~nm})$, medium $(12-22 \mathrm{~nm})$, and medium to large $(17-30 \mathrm{~nm})$ sized anatase particles, respectively. The corresponding Pd NP size distributions from these same samples are shown in Figure $2 \mathrm{c}$ and have mean values of the $2.3-3.1 \mathrm{~nm}$ range which is consistent with the starting size of the PVA stabilized Pd colloid.
We further characterized the surface composition and valence states of all as-synthesised Pd NPs dispersed on various anatase particles, as shown in the XPS spectra (Figure 3). Survey spectra
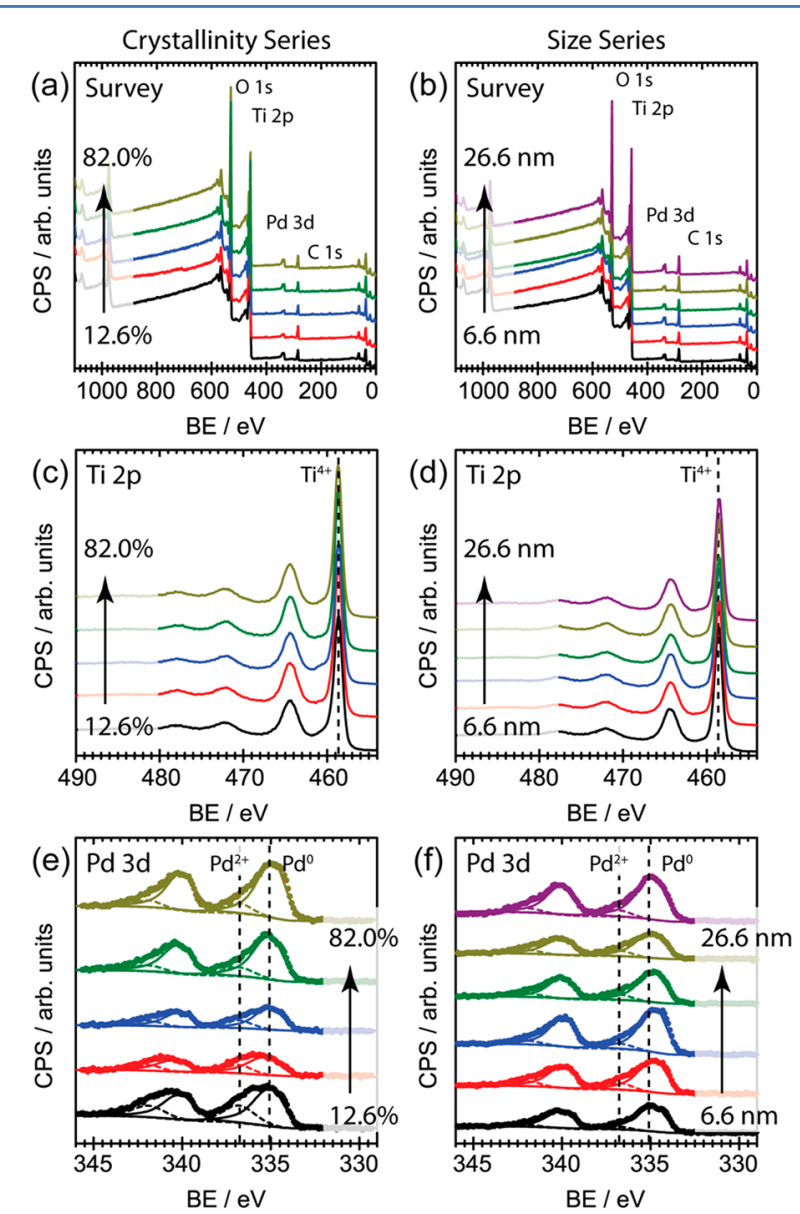

Figure 3. Survey XPS spectra of Pd NPs supported on (a) $9 \mathrm{~nm}$ anatase having different degrees of crystallinity and (b) $82 \%$ crystallinity with varying mean crystallite size, respectively. (c-f) High resolution Ti $2 p$ and $\mathrm{Pd} 3 \mathrm{~d}$ spectra of sample sets with varying $\mathrm{TiO}_{2}$ crystallinity and varying mean crystallite size, respectively. The solid and dashed lines are fitting results of the raw data (dots). The binding energies of $\mathrm{Ti}^{4+}, \mathrm{Pd}^{0}$, and $\mathrm{Pd}^{2+}$ are indicated by dotted lines, respectively. ${ }^{49,50}$ All catalysts have a nominal Pd loading of 1 wt \%.

of the photocatalysts as a function of the $\mathrm{TiO}_{2}$ crystallinity (Figure $3 \mathrm{a}$ ) and mean crystallite size (Figure $3 \mathrm{~b}$ ) revealed that within the limit of detectability they only consisted of $\mathrm{Ti}, \mathrm{O}, \mathrm{Pd}$, and adventitious C. Quantitative analysis showed that the surface concentrations of Pd were $\sim 2.5$ wt $\%$ for all samples, which is slightly higher than the nominal 1 wt \% bulk Pd concentration due to the preferential location of Pd at the anatase surface.

High resolution $\mathrm{Ti} 2 \mathrm{p}$ spectra of the crystallinity series (Figure 3c) and mean crystallite size series (Figure $3 \mathrm{~d}$ ) suggest that, as expected, exclusively $\mathrm{Ti}^{4+}$ is presented in all cases, again confirming that the anatase $\mathrm{TiO}_{2}$ particles remained within the sol-immobilization process essentially unchanged. The Pd 3d spectra of all samples with different crystallinity and crystallite size are shown in Figure 3e,f, respectively. The Pd 3d signals can be deconvoluted at least into two peaks, indicating the presence of both $\mathrm{Pd}^{0}$ and $\mathrm{Pd}^{2+}$ species. ${ }^{50}$ However, the $\mathrm{Pd}^{0} / \mathrm{Pd}^{2+}$ ratios varied significantly depending on the degree of crystallinity exhibited by the anatase $\mathrm{TiO}_{2}$ particles. While the $\mathrm{Pd}^{0} / \mathrm{Pd}^{2+}$ ratio increased from 2.4 to 6.7 following the increase of crystallinity 
from $12.6 \%$ to $82 \%$, increasing the crystallite size of anatase showed negligible effect on the $\mathrm{Pd}^{0} / \mathrm{Pd}^{2+}$ ratio, which remained at $\sim 7$ (see Table S2 in Supporting Information). ${ }^{48}$ In conjunction with the evidence from the corresponding XRD patterns (Figure 1a), we can conclude that a mixture of $\mathrm{Pd} / \mathrm{PdO} \mathrm{NPs}$ has been deposited on anatase particles with low crystallinity, whereas for highly crystalline anatase, mainly metallic Pd NPs are formed that are possibly covered with an ultrathin PdO layer.

Effect of $\mathrm{TiO}_{2}$ Structural Parameters on the Photocatalytic Performance. We first studied the effect of the $\mathrm{Pd}$-anatase interaction on photocatalytic $\mathrm{H}_{2}$ production, as shown in Figure 4. For comparative purposes, a sol-immobilized
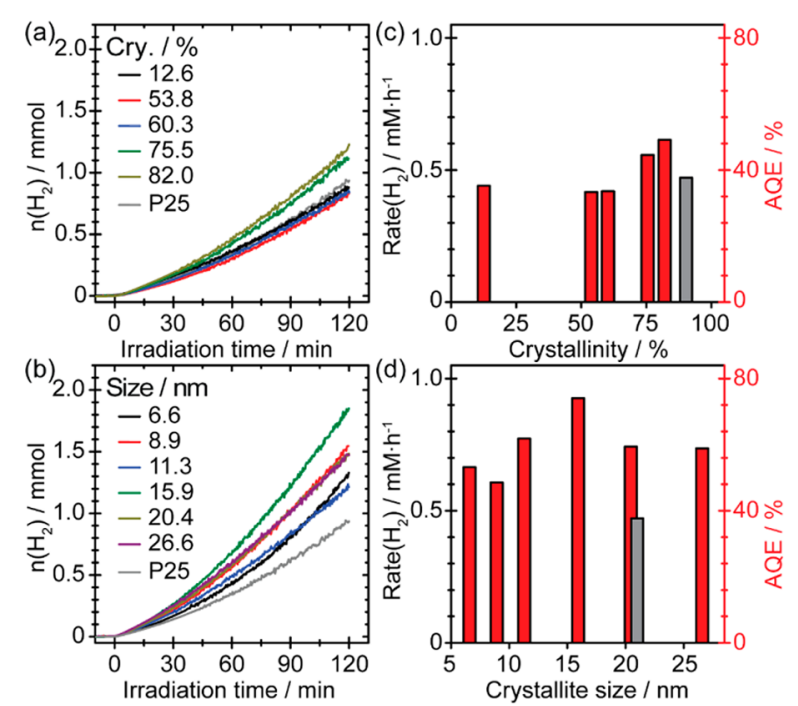

Figure 4. Time resolved photocatalytic $\mathrm{H}_{2}$ evolution using 1 wt \% Pd NPs supported on (a) $9 \mathrm{~nm}$ anatase with different crystallinity and (b) $82 \%$ crystallinity and varying crystallite size, respectively. A 1 wt $\%$ Pd NPs on Degussa P25 was tested for comparison. A 25 vol \% of ethanol solution was used for all tests. (c, d) Derived $\mathrm{H}_{2}$ production rates and $A Q E$ as a function of varying crystallinity and varying crystallite size of the anatase particles. AQE $=2 n\left(\mathrm{H}_{2}\right) / n$ (incident photons), where $n\left(\mathrm{H}_{2}\right)$ and $n$ (incident photons) are the numbers of generated $\mathrm{H}_{2}$ and incident photons, respectively. ${ }^{48}$

Pd cocatalyst supported on a commercial $\mathrm{TiO}_{2}$ (Degussa P25) was also tested. Time resolved $\mathrm{H}_{2}$ evolution (Figure 4a,b) suggests that all $\mathrm{Pd}$ /anatase variants can generate $\mathrm{H}_{2}$ upon $\mathrm{UV}$ irradiation; however, the performance of these variants varied significantly depending on the nature of the anatase particles. To better visualize the effects of varying $\mathrm{TiO}_{2}$ crystallinity and crystallite size, we calculated the $\mathrm{H}_{2}$ production rate and apparent quantum efficiency (AQE) of all $\mathrm{Pd} / \mathrm{TiO}_{2}$ photocatalysts, as shown in Figure $4 c, d$, respectively. ${ }^{48}$ While poorly crystalline $9 \mathrm{~nm} \mathrm{TiO}_{2}$ particles $(<60 \%)$ showed nearly identical performance for $\mathrm{H}_{2}$ evolution, a slight increase in the performance was observed for those samples displaying a higher degree of crystallinity $(>60 \%)$. Interestingly, increasing the crystallite size of the most crystalline $\mathrm{TiO}_{2}$ particles $(\sim 82 \%)$ from 6.6 to $15.9 \mathrm{~nm}$ caused a significant enhancement in performance, but a further increase of the crystallite size to $26.6 \mathrm{~nm}$ deactivated the photoreactivity. Remarkably, the Pd NPs supported on the $15.9 \mathrm{~nm}, 82 \%$ crystalline anatase particles presented an extremely high AQE for $\mathrm{H}_{2}$ evolution ( $78 \%$ ), which was about double that found for Pd NPs with similar particle size supported on commercial $\mathrm{P} 25 \mathrm{TiO}_{2}$. Such an AQE value is even higher than that reported previously for the $\mathrm{Au}_{\text {core }} \mathrm{Pd}_{\text {shell }}$ cocatalyst on P25 (73\%), which at the time of publication was superior to that of any photocatalyst reported using renewable organic chemicals as scavengers. $^{27}$

We further investigated the correlation of the $\mathrm{Pd}$-anatase interaction and photocatalytic oxidation performance through a phenol decomposition reaction, as shown in Figure 5. Previous

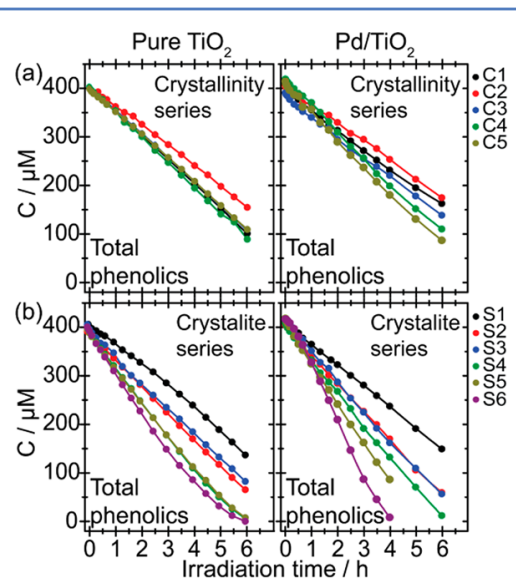

Figure 5. Evolution of total phenolics during photocatalytic phenol decomposition using the $9 \mathrm{~nm}$ pristine anatase (left column) and $1 \mathrm{wt} \%$ Pd NPs modified anatase (right column) with different crystallinity (a), and using the $82 \%$ pristine anatase (left column) and $1 \mathrm{wt} \%$ Pd NPs modified anatase (right column) with different mean crystallite size (b). ${ }^{41}$

kinetic analysis based on in situ UV-vis and MS spectrometry suggested that the optimum performance for full phenol oxidation was always observed for samples that produced the minimum fraction of phenolic species (i.e., hydroquinone and benzoquinone), as these redox couples consume the photogenerated charge carriers continuously, thus reducing the conversion of phenol to $\mathrm{CO}_{2} \cdot{ }^{39,41}$ Therefore, the decomposition rate of total phenolic species shown in Figure 5 reflects the performance of the photocatalysts for the full oxidation of phenol. For $9 \mathrm{~nm} \mathrm{TiO}_{2}$ with different degrees of crystallinity, surface decoration with Pd NPs showed negligible effects on the phenol decomposition rate for the more crystalline $\mathrm{TiO}_{2}$ particles $(>75 \%)$ but a decrease in phenol decomposition for the less crystalline $\mathrm{TiO}_{2}(<60 \%)$ particles, respectively (Figure 5a). We did observe that the formation and decomposition of phenolic intermediates (hydroquinone and benzoquinone) were slightly improved upon increasing the crystallinity of the $\mathrm{TiO}_{2}$ particles (Figure S8b,c), ${ }^{46}$ which resulted in a minor enhancement toward the full decomposition of phenol using $\mathrm{Pd} / \mathrm{TiO}_{2}$ compared to that of their pristine $\mathrm{TiO}_{2}$ counterparts.

Interestingly, Pd NPs supported on highly crystalline (82\%) $\mathrm{TiO}_{2}$ with tunable crystallite size presented a different phenomenon. While Pd NPs supported on small anatase particles $(<15.9 \mathrm{~nm})$ showed identical performance in phenol decomposition compared to their Pd-free counterparts, a further increase in the mean size of anatase $(>15.9 \mathrm{~nm})$ boosted the photocatalytic oxidation of phenol significantly (Figure 5b). The evolution of hydroquinone and benzoquinone using undecorated and Pd-decorated $\mathrm{TiO}_{2}$ (82\% crystallinity) with different mean crystallite sizes are also presented in Figure S8f,g, respectively. ${ }^{41,46}$ These plots clearly reveal that the interaction of Pd with anatase can better promote the decomposition of both intermediates when the mean size of the anatase crystallites exceeds $\sim 15.9 \mathrm{~nm}$, which eventually accelerates the complete decomposition of phenol. 
We can satisfactorily explain some of the observed phenomena using some prior experience and knowledge. For example, amorphous $\mathrm{TiO}_{2}$ is generally considered to be poor for photocatalysis. ${ }^{41}$ Furthermore, the optimized photocatalytic $\mathrm{H}_{2}$ production noted for medium sized crystalline anatase decorated with Pd can be considered as a deliberate trade-off between surface area effects and quantum size effects. However, the underlying mechanism is not sufficiently well-understood to fully explain the following issues: (i) the fact that increasing the degree of crystallinity of the anatase does not seem to significantly affect the photocatalytic $\mathrm{H}_{2}$ production and phenol decomposition, and (ii) the optimized crystallite size required for photocatalytic $\mathrm{H}_{2}$ production and phenol decomposition is markedly different (i.e., $15.9 \mathrm{~nm}$ versus $26.6 \mathrm{~nm}$ ). Surface science studies on model $\mathrm{TiO}_{2}$ photocatalysts revealed that surface defects (i.e., vacancies and adatoms) and bulk defects affect the charge transfer and trapping kinetics, which in turn control the surface adsorbed species that influence the reaction pathways and determine catalytic performance. ${ }^{15,51}$ However, the above conclusions were drawn from data collected using the surface science approach based on single crystal $\mathrm{TiO}_{2}$ (normally a reduced rutile phase) under ultrahigh vacuum conditions, which are not directly comparable to the $\mathrm{TiO}_{2}$ NPs (normally pure anatase or mixed anatase/rutile polymorphs [P25]) that are used in real photocatalytic reactions under ambient conditions.

To rationalize the $\mathrm{Pd}$-anatase interaction under different reaction conditions, we performed solid state ESR analysis on a selected subset of anatase samples and their corresponding Pd decorated counterparts, as shown in Figure 6. When pristine
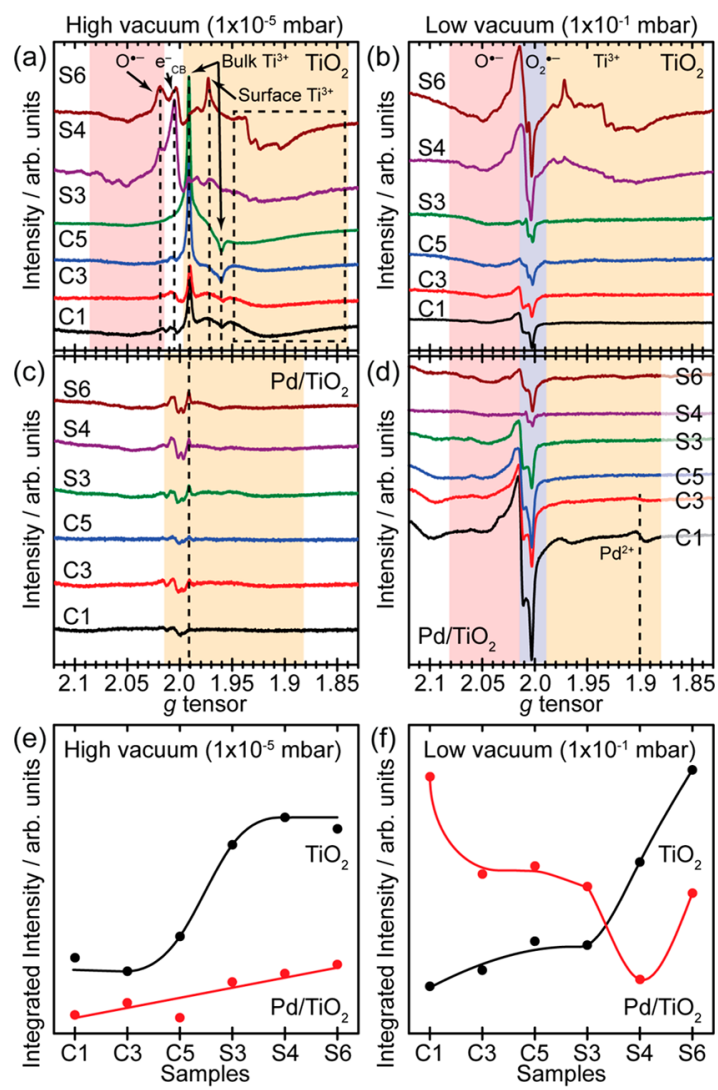

Figure 6. ESR spectra of selected pristine $\mathrm{TiO}_{2}$ and 1 wt $\% \mathrm{Pd} / \mathrm{TiO}_{2}$ samples that have been UV irradiated for $30 \mathrm{~min}$ at $77 \mathrm{~K}$ under high vacuum ( $a$ and $c$ ) and low vacuum (b and d), respectively. (e, f) Integrated intensities of all ESR spectra recorded under high vacuum and low vacuum, respectively. Lines in parts e and $\mathrm{f}$ are guidelines only.
$\mathrm{TiO}_{2}$ samples were irradiated under high vacuum (Figure 6a, $P_{\text {cell }}=10^{-5}$ mbar , well-characterized $\mathrm{Ti}^{3+}$ centers, $\mathrm{CB}$ electrons $\left(\mathrm{e}^{-} \mathrm{CB}\right)$, and $\mathrm{O}^{\bullet-}$ were formed as expected due to charge separation $\left(\mathrm{e}^{-}+\mathrm{Ti}^{4+} \rightarrow \mathrm{Ti}^{3+}, \mathrm{O}^{2-}+\mathrm{h}^{+} \rightarrow \mathrm{O}^{\bullet-}\right)$. Note that $\mathrm{e}^{-}{ }_{\mathrm{CB}}$ showed a $g$ value of 2.003, which can effectively be considered as "free electrons" $(g=2.0023)$. The ESR signal at $g=2.003$ could also be induced by the defect states at particle-particle interfaces on reduced anatase, ${ }^{52}$ but such contribution should be negligible in our case as all samples consist of stoichiometric $\mathrm{TiO}_{2}$. However, the relative concentrations of different radical species varied significantly as the crystallinity changed. While mainly $\mathrm{Ti}^{3+}$ species in regular bulk lattice positions (bulk $\mathrm{Ti}^{3+}, g_{\perp}=1.992$, $\left.g_{\|}=1.960\right)$ were detected for $\mathrm{TiO}_{2}$ with poor crystallinity or small sizes (C1, C3, C5, and $\mathrm{S} 3),{ }^{53} \mathrm{Ti}^{3+}$ in a disordered environment (near-surface $\mathrm{Ti}^{3+}, g=1.93$ ), $\mathrm{e}^{-}{ }_{\mathrm{CB}}$, and $\mathrm{O}^{\bullet-}$ were the dominant species found for highly crystalline $\mathrm{TiO}_{2}$ with larger crystallite sizes (S4 and S6) ${ }^{54}$ Because the most intense surface $\mathrm{Ti}^{3+}$ features were observed on sample $\mathrm{S6}$, and the extensive bulk $\mathrm{Ti}^{3+}$ features were observed on samples $\mathrm{C} 1, \mathrm{C} 3$, $\mathrm{C5}$, and S4, we surmise that large anatase is responsible for the surface $\mathrm{Ti}^{3+}$ and small anatase is the source for the bulk $\mathrm{Ti}^{3+}$. Moreover, increasing the crystallinity from $12.6 \%$ (C1) to $60.3 \%$ (C3) and then to $82 \%$ (C5 and S3) solely resulted in an increase of the bulk $\mathrm{Ti}^{3+}$, whereas most $\mathrm{e}^{-}$Св converted to near-surface $\mathrm{Ti}^{3+}$ centers when the $\mathrm{TiO}_{2}$ size grew from $16.4 \mathrm{~nm}$ (S4) to $27 \mathrm{~nm}$ (S6). Therefore, the $\mathrm{e}^{-}{ }_{\mathrm{CB}}$ should be solely generated on medium sized anatase as the corresponding ESR peak was significantly observed on sample S4 and visible on sample S6. Interestingly, the signals of excess charges vanished almost completely in all samples when preformed Pd NPs were immobilized onto the $\mathrm{TiO}_{2}$ particles (see Figure 6c), indicating most of the excited electrons were successfully transferred from $\mathrm{TiO}_{2}$ and localized at $\mathrm{Pd}$ surface sites. In comparison, $\mathrm{Ti}^{3+}$ species in regular bulk lattice positions were predominantly detected for pure P25 after irradiation under high vacuum, which is a similar situation to that of sample S3 (Figure S10a). These trapped electrons can also be transferred to Pd surface sites (Figure S10c). ${ }^{46}$

We also performed similar experiments under low vacuum conditions $\left(P_{\text {cell }}=10^{-1} \mathrm{mbar}\right)$ to examine the effect of oxygen and water upon radical formation under UV irradiation, as shown in Figure $6 \mathrm{~b}, \mathrm{~d}$ for pristine $\mathrm{TiO}_{2}$ and $\mathrm{Pd} / \mathrm{TiO}_{2}$, respectively. Surprisingly, while surface $\mathrm{Ti}^{3+}, \mathrm{O}_{2}{ }^{\bullet-}$, and $\mathrm{O}^{\bullet-}$ were observed for large anatase particles ( $\mathrm{S} 4$ and $\mathrm{S} 6$ ), $\mathrm{O}_{2}{ }^{--}$was the only radical species detected for poorly crystalline or small grain $\mathrm{TiO}_{2}$ samples (C1, C3, C5, and S3), and the intensity was much weaker compared to that observed for samples S4 and S6. The spectra changed considerably in the presence of Pd NPs on $\mathrm{TiO}_{2}$ particles, as shown in Figure 6d. While the characteristic nearsurface $\mathrm{Ti}^{3+}$ signals observed for large pristine anatase vanished due to charge transfer from $\mathrm{TiO}_{2}$ to $\mathrm{Pd}$, weak fingerprints of $\mathrm{Pd}^{2+}$ signals were observed in the low crystallinity sample (C1 and C3), ${ }^{55}$ which agrees well with our XRD and XPS observations. Noticeably, the number of surface $\mathrm{O}_{2}{ }^{\bullet-}$ radicals decreased when increasing the crystallinity from $12.6 \%(\mathrm{C} 1)$ to $60.3 \%(\mathrm{C} 3)$ and to $82 \%$ (C5 and S3), as well as increasing the crystallite size from $9.3 \mathrm{~nm}(\mathrm{C} 5)$ to $11.3 \mathrm{~nm}(\mathrm{~S} 3)$ and to $15.9 \mathrm{~nm}$ (S4), and reached a minimum with a mean size of $15.9 \mathrm{~nm}$ (S4). The concentration of $\mathrm{O}_{2}{ }^{\bullet-}$ radical shown in Figure $6 \mathrm{~d}$ can also be associated with the divergence in the content of medium sized anatase between samples S3, S4, and S6. Surface $\mathrm{Ti}^{3+}$ and $\mathrm{O}_{2}{ }^{\bullet-}$ were the dominant species when pure P25 was irradiated under low vacuum, and the intensity of the $\mathrm{O}_{2}{ }^{\bullet-}$ signal was similar to that of S4 (Figure S10b). However, $\mathrm{Ti}^{3+}$ cations were still evident in the ESR spectra of $\mathrm{Pd}$ 
on P25, indicating the interfacial charge transfer between P25 and $\mathrm{Pd}$ to be relatively poor compared to that of the Pd-anatase system (Figure S10d). ${ }^{46}$

We have further estimated the total numbers of active paramagnetic species by integrating the ESR signals, as shown in Figure 6e,f. Under high vacuum conditions (Figure 6e), small $\mathrm{TiO}_{2}$ particles with low crystallinity $(\mathrm{C} 1, \mathrm{C} 3$, and $\mathrm{C} 5)$ generated far fewer active paramagnetic species compared to that of other $\mathrm{TiO}_{2}$ particles. However, for large $\mathrm{TiO}_{2}$ particles with high crystallinity (S3, S4, and S6), the number of Pd NPs seems to become insufficient for trapping excess $\mathrm{Ti}^{3+}$. Under low vacuum conditions (Figure $6 \mathrm{f}$ ), the densities of surface active paramagnetic species increased sharply only when the crystallinity and size of $\mathrm{TiO}_{2}$ reached certain thresholds ( $>80 \%$ and $>15.9 \mathrm{~nm}$ ), and a minimum concentration of surface $\mathrm{O}_{2}{ }^{\bullet-}$ species was observed for Pd NPs supported on $\mathrm{TiO}_{2}$ with a crystallite size of $15.9 \mathrm{~nm}$ (S4).

Since the density and identity of surface radicals are a reflection of the thermodynamics and kinetics of the charge carriers under reaction conditions, it is crucial to obtain a deep understanding of the charge carriers. In this connection we note that various defects such as $\mathrm{OH}$ species, low coordinated ions, and oxygen vacancies $\left(\mathrm{V}_{\mathrm{O}}\right)$ may exist in pure $\mathrm{TiO}_{2},{ }^{56-58}$ turning it into an n-type semiconductor, where the electrons and holes are the majority and minority charge carriers, respectively. However, in the present study all samples were stoichiometric anatase (see Figure 3 ) that should be close to behaving like intrinsic semiconductors. Nevertheless, excess charge may occur due to minority defects. In the following we focus on the excited electrons for $\mathrm{H}_{2}$ evolution with ethanol as the hole scavenger. As the phenol decomposition is more complicated, we would have to consider both electrons and holes since phenol and $\mathrm{O}_{2}$ have to be oxidized and reduced simultaneously.

In order to reveal the effect of charge carriers on the photocatalytic performance, we have modeled a three-layer anatase $\mathrm{TiO}_{2}$ (101) surface with a $\mathrm{V}_{\mathrm{O}}$ placed at various surface and subsurface (bulk) sites (Figure 7a), and calculated the surface DOS

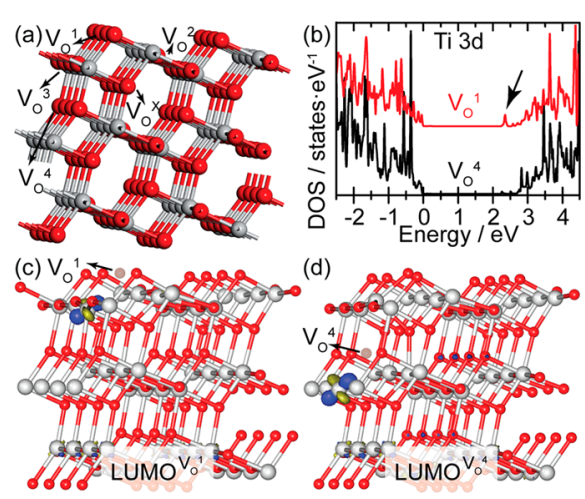

Figure 7. (a) Three-layer anatase (101) surface model with five different oxygen vacancies $\left(V_{O}\right)$. (b) The surface DOS of Ti $3 d$ with $V_{O}{ }^{1}$ and $V_{O}{ }^{4}$. The arrow indicates the midgap state. (c, d) LUMO of the anatase (101) surface with $\mathrm{V}_{\mathrm{O}}{ }^{1}$ and $\mathrm{V}_{\mathrm{O}}{ }^{4}$, respectively. Ti atom: gray. $\mathrm{O}$ atom: red.

of the system with different $\mathrm{V}_{\mathrm{O}}$ and the LUMO distributions, as shown in Figure 7. Our focus here is the creation of $\mathrm{Ti}^{3+}$ in the system rather than the structure of the defects. Here, introducing one $\mathrm{V}_{\mathrm{O}}$ corresponds to the creation of two $\mathrm{Ti}^{3+}$, which is equivalent to two trapped electrons at the $\mathrm{Ti}^{4+}$ sites.

Among these five possible $V_{O}$ sites shown in Figure $7 a, V_{O}{ }^{1}$, $\mathrm{V}_{\mathrm{O}}{ }^{2}, \mathrm{~V}_{\mathrm{O}}{ }^{3}$, and $\mathrm{V}_{\mathrm{O}}{ }^{\mathrm{X}}$ can be assigned to different variants of surface
$V_{O}$, whereas $V_{O}{ }^{4}$ is a subsurface $V_{O}$ defect. The calculated formation energies derived from the model with one single $\mathrm{V}_{\mathrm{O}}{ }^{1}, \mathrm{~V}_{\mathrm{O}}{ }^{2}$, $\mathrm{V}_{\mathrm{O}}{ }^{3}, \mathrm{~V}_{\mathrm{O}}{ }^{\mathrm{X}}$, and $\mathrm{V}_{\mathrm{O}}{ }^{4}$ defect are 3.99, 4.90, 4.57, 4.27, and $3.88 \mathrm{eV}$ at $0 \mathrm{~K}$, respectively (see Figure S11), ${ }^{46}$ indicating that oxygen vacancies are most stable on site 4 (i.e., subsurface) followed by site 1 (surface) rather than on the other sites considered.

The surface DOS shown in Figure $7 \mathrm{~b}$ reveals the effect of $V_{O}{ }^{1}$ and $\mathrm{V}_{\mathrm{O}}{ }^{4}$ on the $\mathrm{Ti} 3 \mathrm{~d}$ orbitals, which constitute the conduction band of $\mathrm{TiO}_{2}$. Interestingly, a midgap state close to the unoccupied Ti $3 \mathrm{~d}$ orbitals was observed for anatase with a $\mathrm{V}_{\mathrm{O}}{ }^{1}$ type defect (see arrow), whereas such a feature was not found for anatase with a $\mathrm{V}_{\mathrm{O}}{ }^{4}$ defect. This $\mathrm{Ti} 3 \mathrm{~d}$ midgap level induced by the surface $\mathrm{V}_{\mathrm{O}}$ provides additional trapping sites for the excited electrons, which could be transferred to the Pd NPs for use in subsequent reduction reactions. Meanwhile, the location of $V_{O}$ has a negligible effect on the $\mathrm{O} 2 \mathrm{p}$ orbitals in the valence band (Figure S12); ${ }^{46}$ thus, the exact location of $\mathrm{V}_{\mathrm{O}}$ does not influence the hole species significantly. The relatively high intensity ESR signals of $\mathrm{O}^{\bullet-}$ observed in samples S4 and S6 in Figure 6a are probably due to the enhanced charge separation caused by the midgap states that originate from surface defects. We further mapped the LUMO of the anatase (101) surface with $\mathrm{V}_{\mathrm{O}}{ }^{1}$ and $\mathrm{V}_{\mathrm{O}}^{4}$, as shown in Figure $7 \mathrm{c}$,d. Obviously the LUMO located at the surface $\mathrm{Ti}$ sites (adjacent to the $\mathrm{V}_{\mathrm{O}}{ }^{1}$ site) is more feasible for charge trapping and subsequent charge transfer than the LUMO located at the subsurface $\mathrm{Ti}$ sites (adjacent to the $\mathrm{V}_{\mathrm{O}}^{4}$ site). Previous surface science studies and DFT calculations showed that the subsurface and bulk $\mathrm{V}_{\mathrm{O}}$ 's are significantly more stable on highly reduced anatase (101). ${ }^{57}$ However, in our case, the samples are all very close to stoichiometric $\mathrm{TiO}_{2}$ (see Figure 3); $\mathrm{TiO}_{2}$ particles are used instead of single crystals, and we are also not working under ultrahigh vacuum conditions. Hence, other surface defects can also potentially be envisaged to be present on our samples that lead to $\mathrm{Ti}^{3+}$ excess charge. ${ }^{57}$ Although all calculation results were derived at $0 \mathrm{~K}$, the electrons that have been trapped at the surface sites should be thermodynamically much easier to utilize for charge transfer even at room temperature. Moreover, the additional unoccupied $\mathrm{Ti} 3 \mathrm{~d}$ states observed for the model with $\mathrm{V}_{\mathrm{O}}{ }^{1}$ should be temperature independent.

We can now correlate the photocatalytic performance with the charge carriers and the properties of the photocatalyst materials by combining the ESR results with the insight of the theoretical calculations. For the $\mathrm{H}_{2}$ evolution reaction, "free electrons" $\left(\mathrm{e}^{-}{ }_{\mathrm{CB}}\right)$ and surface trapped electrons (near-surface $\mathrm{Ti}^{3+}$ ) are thermodynamically and kinetically more favorable to reduce $\mathrm{H}^{+}$to $\mathrm{H}_{2}$ compared to electrons trapped within the subsurface or in the bulk (i.e., lattice $\mathrm{Ti}^{3+}$ ). $\mathrm{Ti}^{3+}$ excess charge is available at the surface of large anatase crystals having high crystallinity, resulting in the formation of surface midgap states below the conduction band, thus improving the charge trapping and transfer efficiency. For anatase with low crystallinity and small crystallite size, $\mathrm{Ti}^{3+}$ excess charge is available predominantly in the subsurface or bulk, which results in a relatively poor charge trapping efficiency. Moreover, the unoccupied states are located at the subsurface or bulk that are unfavorable for interfacial charge transfer, leading to a relatively poor photocatalytic performance. Furthermore, a lower density of surface $\mathrm{O}_{2}{ }^{\bullet-}$ radicals in medium sized anatase is ideal to inhibit reoxidation (i.e., back reactions) of the freshly synthesized $\mathrm{H}_{2}$ during the photocatalytic process. ${ }^{40}$ Accordingly, an optimum level of photocatalytic $\mathrm{H}_{2}$ evolution was observed for highly crystalline $\mathrm{TiO}_{2}(82.6 \%)$ with moderate crystallite size $(15.9 \mathrm{~nm})$. The relatively poor performance of Pd on P25 can mainly be associated with the bulk trapped electrons that require 
extra energy for charge transfer to the Pd NPs. For phenol decomposition, however, a situation is favorable where a dense population of surface radicals exist, which makes breaking of the aromatic rings more feasible. Thus, the best performance for phenol decomposition was observed for highly crystalline $\mathrm{TiO}_{2}$ $(86.3 \%)$ of large size $(26.6 \mathrm{~nm})$.

\section{CONCLUSIONS}

We have synthesised photocatalysts composed of Pd NPs supported on $\mathrm{TiO}_{2}$ (anatase) materials having well-controlled crystallinity and crystallite size. While mainly metallic Pd NPs were deposited on highly crystalline $\mathrm{TiO}_{2}$ regardless of the anatase crystallite size, about $20-30 \%$ of the Pd was presented in the $\mathrm{Pd}^{2+}$ form (i.e., $\mathrm{PdO}$ ) when using poorly crystalline $\mathrm{TiO}_{2}$ particles. We have investigated the interaction of the $\mathrm{Pd}$ cocatalyst with $\mathrm{TiO}_{2}$ for photocatalytic $\mathrm{H}_{2}$ production and phenol decomposition reactions. Tuning the crystallinity of the $\mathrm{TiO}_{2}$ particles showed a negligible effect on the photocatalytic performance of both reactions in comparison to varying the crystallite size. For $\mathrm{H}_{2}$ production, a remarkable apparent quantum efficiency of $\sim 78 \%$ was obtained when using anatase particles with a medium crystallite size of $\sim 16 \mathrm{~nm}$. Meanwhile, an improvement in phenol decomposition was only observed for anatase particles with larger crystallite size $(>20 \mathrm{~nm})$. ESR analysis revealed that larger anatase particles $(>16 \mathrm{~nm})$ offer more near-surface sites for charge trapping, whereas solely bulk trapping sites were observed for smaller anatase. Such additional surface sites benefit both charge storage and charge transfer from $\mathrm{TiO}_{2}$ to the $\mathrm{Pd}$ cocatalyst surface sites, and thus provide a more efficient utilization of charge carriers to enhance $\mathrm{H}_{2}$ evolution and phenol decomposition. Additionally, the presence of $\mathrm{Pd}$ on medium sized anatase particles $(\sim 16 \%)$ limited the formation of $\mathrm{O}_{2}{ }^{\bullet-}$ radicals on $\mathrm{TiO}_{2}$ surfaces, preventing unwanted reoxidation of photogenerated $\mathrm{H}_{2}$. DFT calculations on surface DOS and LUMO distribution illustrate that the surface trapping sites for photoexcited electrons in medium and large grain anatase can indeed be associated with different locations of defects such as $\mathrm{V}_{\mathrm{O}}$ species. Irrespective of the exact nature of the defects, it is clear that surface $\mathrm{Ti}^{3+}$ sites are beneficial for photocatalytic reactions, since they facilitate interfacial charge transfer from $\mathrm{TiO}_{2}$ to the Pd NPs. Our results suggest that varying the size of the semiconductor is an efficient method to tune the electronic interaction between metal NPs and semiconductor to improve the photocatalytic performance. Further investigation on the $\mathrm{Pd}$ size effect, $\mathrm{Pd}^{0}: \mathrm{Pd}^{2+}$ ratio, and $\mathrm{Pd} / \mathrm{TiO}_{2}$ interface may further tune the electronic properties of the material thus improving the photocatalytic performance.

\section{EXPERIMENTAL SECTION}

Sample Preparation. Synthesis of $\mathrm{TiO}_{2}$ Particles. A supercritical synthesis approach using a continuous flow reactor was employed to prepare $\mathrm{TiO}_{2}$ nanoparticles. ${ }^{46}$ Isopropanol mixed with deionized (DI) water and titanium isopropoxide (TTIP, ACROS, 98\%) were used as the supercritical solvent and the reactant, respectively. The crystallinity and crystallite size of pure anatase $\mathrm{TiO}_{2}$ were controlled by tuning the concentration of TTIP, composition of the solvent, flow rate, temperature, and pressure, as listed in Table S1 in the Supporting Information. ${ }^{48}$ The suspensions of as-prepared anatase particles were centrifuged, washed with DI water, and dried overnight at $120^{\circ} \mathrm{C}$. A series of samples were prepared where the crystallinity of anatase was tuned independently from $12 \%$ to $82 \%$ while maintaining a constant crystallite size of $\sim 9 \mathrm{~nm}$ (samples C1-C5). A second series was made where the anatase crystallite size was varied from $\sim 6$ to $\sim 27 \mathrm{~nm}$ while keeping a constant crystallinity of $\sim 82 \%$ (samples $\mathrm{S} 1-\mathrm{S} 6)$, as shown in Figure $S 1$. $^{4,48}$

Deposition of Pd NPs on $\mathrm{TiO}_{2}$ Particles. A standard solimmobilization method was utilized to deposit $1 \mathrm{wt} \%$ of Pd NPs on the various anatase particles described above. ${ }^{32}$ Aqueous solutions of $\mathrm{PdCl}_{2}$ (Johnson Matthey), polyvinyl alcohol (PVA) (1 wt \% aqueous solution, Aldrich, MW $=10000,80 \%$ hydrolyzed), and $\mathrm{NaBH}_{4}(0.1 \mathrm{M})$ were freshly prepared and mixed to generate the Pd colloid for deposition. Immobilization of the Pd colloid was then performed by adding the anatase support into the fresh sol (acidified to $\mathrm{pH} 1-2$ by sulfuric acid) under vigorous stirring conditions. The catalyst slurry was then filtered, washed thoroughly with DI water, and dried at $120{ }^{\circ} \mathrm{C}$ overnight. For comparative purposes, a 1 wt \% Pd supported on commercial $\mathrm{TiO}_{2}$ (Degussa P25) was also prepared by solimmobilization.

Materials Characterization. Powder X-ray diffraction (XRD) was used to acquire crystallographic information on the samples by using an X-ray diffractometer (SmartLab, Rigaku) operating with $\mathrm{Cu} \mathrm{K} \alpha$ radiation. A scan rate of $0.04 \mathrm{deg} \mathrm{s}^{-1}$ and integration time of $10.0 \mathrm{~s}$ were used for all measurements. Rietveld refinement was applied to determine the peak area and thus the crystallite size from the diffraction patterns. ${ }^{41,59}$ The crystallinity of the sample is defined as the percentage of crystallites in a mixture of crystalline and amorphous material, and thus can be measured by mixing the sample with a $\mathrm{CaF}_{2}$ reference ( $1: 1$ weight ratio), which is $100 \%$ crystalline. The crystallinity of the sample was calculated by comparing the integrated areas of the diffraction peaks of anatase (101) with $\mathrm{CaF}_{2}(111)$ by the following equation: ${ }^{60}$

$$
\text { crystallinity }=0.763 \times A_{\text {anatase }(101)} / A_{\mathrm{CaF}_{2}(111)} \times 100 \%
$$

High angle annular dark-field (HAADF) images of some of the photocatalyst samples were acquired using a $200 \mathrm{kV} \mathrm{JEOL} \mathrm{ARM}$ 200CF scanning transmission electron microscope (STEM) equipped with a CEOS probe aberration corrector. The samples for STEM analysis were prepared by dry dispersing the catalyst powder onto a holey carbon TEM grid.

A Kratos Axis Ultra spectrometer equipped with a monochromatic $\mathrm{Al} \mathrm{K} \alpha$ source $(10 \mathrm{~mA}, 15 \mathrm{kV})$ was employed to perform X-ray photoelectron spectroscopy (XPS) analysis. Pass energies of 160 and $40 \mathrm{eV}$ were used for survey scans and high resolution scans, respectively. Calibration of the binding energy was referenced to adventitious carbon, which has a binding energy of 284.8 for the C 1s peak.

Photocatalytic Performance Measurements. Photocatalytic $\mathrm{H}_{2}$ production and phenol decomposition reactions were both performed to evaluate the performance of each material. Prior to the experiment, fresh photocatalyst $(50 \mathrm{mg})$ was dispersed in DI water and subsequently cleaned by UV irradiation (Optimax 365, $365 \mathrm{~nm} \mathrm{LED,} \mathrm{photon} \mathrm{flux:} 4 \times 10^{17}$ photons s$^{-1}$ ) for $2 \mathrm{~h}$ to remove the PVA ligand.

For $\mathrm{H}_{2}$ production, $6.25 \mathrm{~mL}$ of ethanol (99 vol \%) was added to the reactor to form a $25 \mathrm{vol} \%$ ethanol-catalyst-water suspension $(25 \mathrm{~mL})$, which was transferred to a leak-tight reactor that was connected to a quadruple mass spectrometer (QMS, Hiden HPR-20) for the analysis of evolved $\mathrm{H}_{2}$. The reactor was then evacuated using a bypass pump until the dissolved $\mathrm{O}_{2}$ level was reduced to below $5 \mu \mathrm{M}$. UV irradiation of $2 \mathrm{~h}$ duration was then employed to photocatalytically evolve $\mathrm{H}_{2}$ under conditions of continuous stirring at room temperature using the same LED light source as described above. The partial pressures 
of $m / e^{-}=2\left(\mathrm{H}_{2}\right), 18\left(\mathrm{H}_{2} \mathrm{O}\right), 28\left(\mathrm{~N}_{2}\right), 32\left(\mathrm{O}_{2}\right)$, and $44\left(\mathrm{CO}_{2}\right)$ species were monitored in situ.

For phenol decomposition, $1 \mathrm{~mL}$ of phenol solution $(20 \mathrm{mM})$ was added to the reactor to form a $400 \mu \mathrm{M}$ phenol-catalystwater suspension $(50 \mathrm{~mL})$. An adsorption/desorption equilibrium was achieved by keeping the suspension in the dark for $1 \mathrm{~h}$. Then, UV irradiation was commenced using the aforementioned LED light source to initiate the photocatalytic decomposition of phenol. A $1.5 \mathrm{~mL}$ aliquot of the suspension was collected at given time intervals, centrifuged, and analyzed by UV-vis spectrometry (UV-1800, Shimadzu, JP).

Further details of the photoreactivity measurements and related calculations are summarized in the Supporting Information and can also be found elsewhere. ${ }^{28,39,48}$

ESR Characterization of the Photocatalysts. An X-band Bruker EMX spectrometer equipped with a highly sensitive cavity (ER 4119HS) was utilized to record the ESR spectra of pure anatase and the various $\mathrm{Pd} /$ anatase samples that have been treated under different oxygen partial pressures. This has been realized by evacuating the cell using a turbo pump system $\left(P_{\text {cell }}: 1 \times 10^{-5}\right.$ mbar $)$ or a rotary pump $\left(P_{\text {cell }}: 1 \times 10^{-1} \mathrm{mbar}\right)$, respectively. Before evacuation, the samples $(10 \mathrm{mg})$ were cleaned by UV irradiation for $2 \mathrm{~h}$ at room temperature. The samples were then evacuated under dynamic vacuum at $80{ }^{\circ} \mathrm{C}$ (for low vacuum) and $120{ }^{\circ} \mathrm{C}$ (for high vacuum) to remove excess surface adsorbed water. The evacuated cell was then irradiated using the same UV light for $30 \mathrm{~min}$ at $77 \mathrm{~K}$, and then transferred into the cavity which was held at $120 \mathrm{~K}$ to record ESR spectra. The modulation field and microwave power employed were $100 \mathrm{kHz}$ and $10 \mathrm{~mW}$, respectively. The value of the $g$ tensor for each measurement was determined using a 2,2-diphenyl-1picrylhydrazyl (DPPH) standard. ${ }^{43,61}$

Theoretical Calculations. Density functional theory (DFT) was used to calculate the formation energy of the photoexcited electrons that are trapped at surface and subsurface sites by creating surface and subsurface oxygen vacancies $\left(V_{O}\right)$. Subsequently, the impact of various surface and subsurface $V_{O}$ defects on the surface density of states (DOS) and the distribution of the lowest unoccupied molecular orbitals (LUMO) were also evaluated. A three O-Ti-O layer anatase model (144 atoms) was used to simulate the (101) surface (surface area $10.44 \times$ 15.57 $\AA^{2}$ ). Vienna Ab-Initio Simulation Package (VASP) with the frozen-core projected-augmented wave (PAW) method was used with application of the generalized gradient approximation (GGA) of Perdew-Burke-Ernzerhof (PBE). ${ }^{62-65}$ The Ti 3d states were described by GGA + U with a $U$ value of $3.5 \mathrm{eV}$ to correct for the on-site Coulomb interactions. ${ }^{66,67}$ The energy and the electronic properties of the anatase (101) surface were computed using a plane wave cutoff of $500 \mathrm{eV}$ and a Monkhorst-Pack grid of $(2 \times 2 \times 1) k$-points. ${ }^{68}$ The computational resources for the project were supplied by the Tianhe- 2 in Lvliang, Shanxi province. More details of the calculation parameters can be found in the Supporting Information. ${ }^{46}$

\section{ASSOCIATED CONTENT}

\section{S Supporting Information}

The Supporting Information is available free of charge on the ACS Publications website at DOI: 10.1021/acscatal.6b00982.

Sample preparation and characterization, apparent quantum efficiency, evolution of the phenolic intermediates, additional ESR spectra, and additional calculation details (PDF)

\section{AUTHOR INFORMATION}

\section{Corresponding Authors}

*E-mail: hutch@cardiff.ac.uk.

*E-mail: fbe@inano.au.dk.

\section{Notes}

The authors declare no competing financial interest.

\section{ACKNOWLEDGMENTS}

We acknowledge the financial support from the iNANO Centre through the Danish Strategic Research Council and the Carlsberg Foundation, and the Centre for Materials Crystallography (Denmark National Research Foundation, DNRF93). We also acknowledge the EPSRC (EP/K014854/1) and NSFC (project number 21503257) for financial support. R.S. acknowledges financial support from Syngaschem BV and SynfuelsChina Technology Co. Ltd. for his stay at Cardiff University in 2014. R.S. would like to thank Prof. Damien Murphy at Cardiff University for EPR training and fruitful discussions and Dr. Jose Gracia at SynCat@Beijing for discussions in calculations.

\section{REFERENCES}

(1) Jin, F. M.; Zeng, X.; Liu, J. K.; Jin, Y. J.; Wang, L. Y.; Zhong, H.; Yao, G. D.; Huo, Z. B. Sci. Rep. 2014, 4, 4503-4511.

(2) Tedsree, K.; Li, T.; Jones, S.; Chan, C. W. A.; Yu, K. M. K.; Bagot, P. A. J.; Marquis, E. A.; Smith, G. D. W.; Tsang, S. C. E. Nat. Nanotechnol. 2011, 6, 302-307.

(3) Wong, M. S.; Alvarez, P. J. J.; Fang, Y.-1.; Akçin, N.; Nutt, M. O.; Miller, J. T.; Heck, K. N. J. Chem. Technol. Biotechnol. 2009, 84, 158166.

(4) Liu, J.; Liu, Y.; Liu, N.; Han, Y.; Zhang, X.; Huang, H.; Lifshitz, Y.; Lee, S.-T.; Zhong, J.; Kang, Z. Science 2015, 347, 970-974.

(5) Sastre, F.; Puga, A. V.; Liu, L.; Corma, A.; García, H. J. Am. Chem. Soc. 2014, 136, 6798-6801.

(6) Chong, M. N.; Jin, B.; Chow, C. W. K.; Saint, C. Water Res. 2010, 44, 2997-3027.

(7) Li, R.; Weng, Y.; Zhou, X.; Wang, X.; Mi, Y.; Chong, R.; Han, H.; Li, C. Energy Environ. Sci. 2015, 8, 2377-2382.

(8) Wang, X.; Maeda, K.; Thomas, A.; Takanabe, K.; Xin, G.; Carlsson, J. M.; Domen, K.; Antonietti, M. Nat. Mater. 2009, 8, 76-80.

(9) Wang, L.; Dionigi, F.; Nguyen, N. T.; Kirchgeorg, R.; Gliech, M.; Grigorescu, S.; Strasser, P.; Schmuki, P. Chem. Mater. 2015, 27, 23602366.

(10) Zhang, Y. C.; Du, Z. N.; Li, K. W.; Zhang, M.; Dionysiou, D. D. ACS Appl. Mater. Interfaces 2011, 3, 1528-1537.

(11) Bao, N.; Shen, L.; Takata, T.; Domen, K. Chem. Mater. 2008, 20, $110-117$.

(12) Moniz, S. J. A.; Shevlin, S. A.; Martin, D. J.; Guo, Z.-X.; Tang, J. Energy Environ. Sci. 2015, 8, 731-759.

(13) Nasalevich, M. A.; Becker, R.; Ramos-Fernandez, E. V.; Castellanos, S.; Veber, S. L.; Fedin, M. V.; Kapteijn, F.; Reek, J. N. H.; van der Vlugt, J. I.; Gascon, J. Energy Environ. Sci. 2015, 8, 364-375.

(14) García-López, E.; Marcì, G.; Megna, B.; Parisi, F.; Armelao, L.; Trovarelli, A.; Boaro, M.; Palmisano, L. J. Catal. 2015, 321, 13-22.

(15) Henderson, M. A. Surf. Sci. Rep. 2011, 66, 185-297.

(16) Hoffmann, M. R.; Martin, S. T.; Choi, W. Y.; Bahnemann, D. W. Chem. Rev. 1995, 95, 69-96.

(17) Tachikawa, T.; Fujitsuka, M.; Majima, T. J. Phys. Chem. C 2007, $111,5259-5275$.

(18) Su, R.; Christensen, M.; Shen, Y. B.; Kibsgaard, J.; Elgh, B.; Vang, R. T.; Bechstein, R.; Wendt, S.; Palmqvist, A.; Iversen, B. B.; Besenbacher, F. J. Phys. Chem. C 2013, 117, 27039-27046.

(19) Hernandez-Alonso, M. D.; Fresno, F.; Suarez, S.; Coronado, J. M. Energy Environ. Sci. 2009, 2, 1231-1257.

(20) Martin, D. J.; Qiu, K.; Shevlin, S. A.; Handoko, A. D.; Chen, X.; Guo, Z.; Tang, J. Angew. Chem., Int. Ed. 2014, 53, 9240-9245. 
(21) Scanlon, D. O.; Dunnill, C. W.; Buckeridge, J.; Shevlin, S. A.; Logsdail, A. J.; Woodley, S. M.; Catlow, C. R. A.; Powell, M. J.; Palgrave, R. G.; Parkin, I. P.; Watson, G. W.; Keal, T. W.; Sherwood, P.; Walsh, A.; Sokol, A. A. Nat. Mater. 2013, 12, 798-801.

(22) Kozlov, D. V.; Vorontsov, A. V. J. Catal. 2008, 258, 87-94.

(23) Yang, J.; Wang, D.; Han, H.; Li, C. Acc. Chem. Res. 2013, 46, 1900-1909.

(24) Rawalekar, S.; Mokari, T. Adv. Energy. Mater. 2013, 3, 12-27.

(25) Takai, A.; Kamat, P. V. ACS Nano 2011, 5, 7369-7376.

(26) Subramanian, V.; Wolf, E. E.; Kamat, P. V.J. Am. Chem. Soc. 2004, 126, 4943-4950.

(27) Cozzoli, P. D.; Curri, M. L.; Agostiano, A. Chem. Commun. 2005, $25,3186-3188$.

(28) Su, R.; Tiruvalam, R.; Logsdail, A. J.; He, Q.; Downing, C. A.; Jensen, M. T.; Dimitratos, N.; Kesavan, L.; Wells, P. P.; Bechstein, R.; Jensen, H. H.; Wendt, S.; Catlow, C. R. A.; Kiely, C. J.; Hutchings, G. J.; Besenbacher, F. ACS Nano 2014, 8, 3490-3497.

(29) Priebe, J. B.; Radnik, J.; Lennox, A. J. J.; Pohl, M.-M.; Karnahl, M.; Hollmann, D.; Grabow, K.; Bentrup, U.; Junge, H.; Beller, M.; Brückner, A. ACS Catal. 2015, 5, 2137-2148.

(30) Tsukamoto, D.; Shiraishi, Y.; Sugano, Y.; Ichikawa, S.; Tanaka, S.; Hirai, T. J. Am. Chem. Soc. 2012, 134, 6309-6315.

(31) Murdoch, M.; Waterhouse, G. I. N.; Nadeem, M. A.; Metson, J. B.; Keane, M. A.; Howe, R. F.; Llorca, J.; Idriss, H. Nat. Chem. 2011, 3, 489492.

(32) Su, R.; Forde, M. M.; He, Q.; Shen, Y.; Wang, X.; Dimitratos, N.; Wendt, S.; Huang, Y.; Iversen, B. B.; Kiely, C. J.; Besenbacher, F.; Hutchings, G. J. Dalton Trans. 2014, 43, 14976-14982.

(33) Paramasivam, I.; Macak, J. M.; Schmuki, P. Electrochem. Commun. 2008, 10, 71-75.

(34) Chen, X. B.; Liu, L.; Yu, P. Y.; Mao, S. S. Science 2011, 331, 746750.

(35) Maeda, K.; Teramura, K.; Lu, D. L.; Saito, N.; Inoue, Y.; Domen, K. Angew. Chem., Int. Ed. 2006, 45, 7806-7809.

(36) Mizukoshi, Y.; Sato, K.; Konno, T. J.; Masahashi, N. Appl. Catal., B 2010, 94, 248-253.

(37) Primo, A.; Corma, A.; Garcia, H. Phys. Chem. Chem. Phys. 2011, 13, 886-910.

(38) Mogyorósi, K.; Kmetykó, Á.; Czirbus, N.; Veréb, G.; Sipos, P.; Dombi, A. React. Kinet. Catal. Lett. 2009, 98, 215-225.

(39) Su, R.; Tiruvalam, R.; He, Q.; Dimitratos, N.; Kesavan, L.; Hammond, C.; Lopez-Sanchez, J. A.; Bechstein, R.; Kiely, C. J.; Hutchings, G. J.; Besenbacher, F. ACS Nano 2012, 6, 6284-6292.

(40) Li, Y. H.; Xing, J.; Chen, Z. J.; Li, Z.; Tian, F.; Zheng, L. R.; Wang, H. F.; Hu, P.; Zhao, H. J.; Yang, H. G. Nat. Commun. 2013, 4, 25002507.

(41) Wang, X. Q.; Sø, L.; Su, R.; Wendt, S.; Hald, P.; Mamakhel, A.; Yang, C. X.; Huang, Y. D.; Iversen, B. B.; Besenbacher, F. J. Catal. 2014, 310, $100-108$.

(42) Hurum, D. C.; Agrios, A. G.; Gray, K. A.; Rajh, T.; Thurnauer, M.

C. J. Phys. Chem. B 2003, 107, 4545-4549.

(43) Carter, E.; Carley, A. F.; Murphy, D. M. J. Phys. Chem. C 2007, $111,10630-10638$.

(44) Matthey, D.; Wang, J. G.; Wendt, S.; Matthiesen, J.; Schaub, R.; Lægsgaard, E.; Hammer, B.; Besenbacher, F. Science 2007, 315, 16921696.

(45) Porsgaard, S.; Jiang, P.; Borondics, F.; Wendt, S.; Liu, Z.; Bluhm, H.; Besenbacher, F.; Salmeron, M. Angew. Chem., Int. Ed. 2011, 50, 2266-2269.

(46) Hald, P.; Becker, J.; Bremholm, M.; Pedersen, J. S.; Chevallier, J.; Iversen, S. B.; Iversen, B. B. J. Solid State Chem. 2006, 179, 2674-2680.

(47) Ganji, S.; Bukya, P.; Vakati, V.; Rao, K. S. R.; Burri, D. R. Catal. Sci. Technol. 2013, 3, 409-414.

(48) Details for sample synthesis and photocatalytic tests, additional TEM and XPS characterizations, and theoretical calculations can be found in Supporting Information.

(49) Su, R.; Bechstein, R; So, L.; Vang, R. T.; Sillassen, M.; Esbjornsson, B.; Palmqvist, A.; Besenbacher, F. J. Phys. Chem. C 2011, $115,24287-24292$.
(50) Noack, K.; Zbinden, H.; Schlögl, R. Catal. Lett. 1990, 4, 145-155.

(51) Henderson, M. A.; Lyubinetsky, I. Chem. Rev. 2013, 113, 44284455.

(52) Baumann, S. O.; Elser, M. J.; Auer, M.; Bernardi, J.; Hüsing, N.; Diwald, O. Langmuir 2011, 27, 1946-1953.

(53) Chiesa, M.; Paganini, M. C.; Livraghi, S.; Giamello, E. Phys. Chem. Chem. Phys. 2013, 15, 9435-9447.

(54) Barolo, G.; Livraghi, S.; Chiesa, M.; Paganini, M. C.; Giamello, E. J. Phys. Chem. C 2012, 116, 20887-20894.

(55) Vedyagin, A. A.; Volodin, A. M.; Stoyanovskii, V. O.; Mishakov, I. V.; Medvedev, D. A.; Noskov, A. S. Appl. Catal., B 2011, 103, 397-403.

(56) Mi, J.-L.; Jensen, K. M. O.; Tyrsted, C.; Bremholm, M.; Iversen, B. B. CrystEngComm 2015, 17, 6868-6877.

(57) He, Y.; Dulub, O.; Cheng, H.; Selloni, A.; Diebold, U. Phys. Rev. Lett. 2009, 102, 106105.

(58) Di Valentin, C.; Pacchioni, G.; Selloni, A. J. Phys. Chem. C 2009, 113, 20543-20552.

(59) Rietveld, H. J. Appl. Crystallogr. 1969, 2, 65-71.

(60) Jensen, H.; Joensen, K.; Jørgensen, J.-E.; Pedersen, J.; Søgaard, G. J. Nanopart. Res. 2004, 6, 519-526.

(61) Adamski, A.; Spałek, T.; Sojka, Z. Res. Chem. Intermed. 2003, 29, $793-804$.

(62) Kresse, G.; Joubert, D. Phys. Rev. B: Condens. Matter Mater. Phys. $1999,59,1758-1775$.

(63) Kresse, G.; Furthmüller, J. Phys. Rev. B: Condens. Matter Mater. Phys. 1996, 54, 11169-11186.

(64) Kresse, G.; Hafner, J. Phys. Rev. B: Condens. Matter Mater. Phys. 1994, 49, 14251-14269.

(65) Perdew, J. P.; Burke, K.; Ernzerhof, M. Phys. Rev. Lett. 1996, 77, 3865-3868.

(66) Dudarev, S. L.; Botton, G. A.; Savrasov, S. Y.; Humphreys, C. J.; Sutton, A. P. Phys. Rev. B: Condens. Matter Mater. Phys. 1998, 57, 15051509.

(67) Cheng, H.; Selloni, A. J. Chem. Phys. 2009, 131, 054703.

(68) Blöchl, P. E. Phys. Rev. B: Condens. Matter Mater. Phys. 1994, 50, 17953-17979. 